\title{
Matrix-Compatible Sorbent Coatings Based on Structurally-Tuned Polymeric Ionic Liquids for the Determination of Acrylamide in Brewed Coffee and Coffee Powder using Solid-Phase Microextraction
}

\author{
Cecilia Cagliero, ${ }^{\mathrm{b}}$ He Nan, ${ }^{\text {a }}$ Carlo Bicchi, ${ }^{\mathrm{b}}$ and Jared L. Anderson ${ }^{\mathrm{a}, *}$ \\ aDepartment of Chemistry, Iowa State University, Ames, IA 50011 USA \\ ${ }^{b}$ Dipartimento di Scienza e Tecnologia del Farmaco, Università degli Studi di Torino, \\ I-10125 Torino, Italy
}

\begin{abstract}
Nine crosslinked polymeric ionic liquid (PIL)-based SPME sorbent coatings were designed and screened in this study for the trace level determination of acrylamide in brewed coffee and coffee powder using gas chromatography-mass spectrometry (GC-MS). The structure of the ionic liquid (IL) monomer was tailored by introducing different functional groups to the cation and the nature of the IL crosslinker was designed by altering both the structure of the cation as well as counteranions. The extraction efficiency of the new PIL coatings towards acrylamide was investigated and compared to a previously reported PIL sorbent coating. All PIL fibers exhibited excellent analytical precision and linearity. The PIL fiber coating consisting of 50\% 1,12-di(3vinylbenzylbenzimidazolium)dodecane dibis[(trifluoromethyl)sulfonyl]imide as IL crosslinker in 1vinyl-3-(10-hydroxydecyl)imidazolium bis[(trifluoromethyl)sulfonyl]imide IL monomer resulted in a limit of quantitation of $0.5 \mu \mathrm{g} \mathrm{L}^{-1}$ with in-solution SPME sampling. The hydroxyl moiety appended to the IL cation was observed to significantly increase the sensitivity of the PIL coating toward acrylamide. The quantitation of acrylamide in brewed coffee and coffee powder was performed using the different PIL-based fibers by the method of standard addition after a quenching reaction using ninhydrin to inhibit the formation of interfering acrylamide in the GC inlet, mainly by asparagine thermal degradation. Excellent repeatability with relative standard deviations below $10 \%$ were obtained on the real coffee samples and the structure of the coatings appeared intact by
\end{abstract}


scanning electron microscopy after coffee sampling proving the matrix-compatibility of the PIL sorbent coatings.

\section{Keywords}

Acrylamide; Coffee; Polymeric ionic liquids; Solid-phase microextraction; Gas Chromatography-Mass Spectrometry

*Corresponding author

Jared L. Anderson

Department of Chemistry

1605 Gilman Hall

Iowa State University, Ames, IA 50011

andersoj@iastate.edu

515-294-8356 


\section{Introduction}

Acrylamide is an unsaturated amide formed primarily through the Maillard reaction when carbohydrate-rich foods are subjected to high temperatures during cooking or thermal processing [1-3]. The toxicological properties of acrylamide are becoming better understood and include neurotoxicity, genotoxicity, carcinogenicity, and reproductive toxicity [4, 5]. Acrylamide has been observed in a number of food matrices. Coffee has been of particular high concern because the roasting of coffee beans produces acrylamide levels that are among the highest of food products [6]. The concentration of acrylamide in coffee beans depends on the coffee species as well as the degree of roasting and usually varies within a range of 35-600 $\mu \mathrm{g} \mathrm{kg}^{-1}$ [7]. Lower levels can be expected in coffee beverages due to dilution effects, although acrylamide can easily be transferred from coffee powder to the beverage due to its high water solubility $[6,7]$.

The analysis of acrylamide in food products is still a significant analytical challenge because of its chemical characteristics and its inherent trace-level concentration. The analytical determination of acrylamide is usually performed by high performance liquid chromatography (HPLC) coupled to mass spectrometry (MS) or tandem MS (MS/MS) [8, 9], or by gas chromatography-mass spectrometry (GC-MS) [10,11]. The analysis of acrylamide in food always requires several pretreatment/cleanup steps. Conventional extraction techniques use solid phase extraction (SPE) to purify crude sample extracts prior to the analysis $[1,9]$. However, due to the multiple SPE steps, these methods are often time-consuming and achieve unsatisfactory limits of detection (LOD).

In a recent study, the authors described a simple and rapid sampling method employing a polymeric ionic liquid (PIL) sorbent coating for in-solution solid-phase microextraction (SPME) coupled to GC-MS for the analysis of acrylamide in brewed coffee and coffee powder [12]. The crosslinked PIL sorbent coating demonstrated superior sensitivity in the extraction of this compound compared to all commercially available SPME coatings. Ninhydrin was employed as a 
quenching reagent during extraction to inhibit the production of additional acrylamide in the inlet of the gas chromatograph by the extraction of asparagine and glucose within the coffee matrix. The PIL fiber provided a limit of quantitation for acrylamide of $10 \mu \mathrm{g} \mathrm{L}^{-1}$, thus achieving comparable results to those of the ISO method in the analysis of coffee powder samples.

The ability to design PIL-based coatings to be matrix compatible is of high interest and has led us to explore the effect of their chemical structure on acrylamide extraction efficiency from coffee samples. In this manuscript, we report a series of nine crosslinked PIL-based SPME sorbent coatings designed to increase the extraction efficiency of acrylamide. The structure of the IL monomer was tailored by introducing different functional groups to the cation and the nature of the crosslinker was designed both by modifying the structure of the cation and/or combining it with different counteranions. The extraction efficiency of the new PIL coatings towards acrylamide was investigated and compared to the previously reported PIL sorbent coating. The matrix-compatibility of the PIL-based fibers with complex real-world samples was also proven by quantifying acrylamide in brewed coffee and coffee powder.

\section{Experimental}

\subsection{Materials}

Acrylamide (99.9\%), ninhydrin, menthol (99\%), acrylonitrile (99\%), 1-chlorohexadecane (95\%), 1,12-dibromododecane (98\%), 4-vinylbenzyl chloride (90\%), 10-bromodecanoic acid (95\%), 10chloro-1-decanol (90\%), 1-vinylimidazole $(\geqslant 99 \%)$, imidazole $(\geqslant 99 \%)$, vinyltrimethoxysilane (VTMS) (98\%), and 2-hydroxyl-2-methylpropiophenone (DAROCUR 1173) (>96\%) were purchased from Sigma-Aldrich (St. Louis, MO, USA). Acetonitrile, acetone, methanol, ethanol, isopropanol, ethyl acetate, chloroform, and dimethylsulfoxide were also purchased from SigmaAldrich with purities equal to or higher than $99 \%$. Hydrogen peroxide $(30 \%, \mathrm{w} / \mathrm{w})$, glacial acetic acid, hydrochloric acid, silver nitrate, ammonium hydroxide (28-30\% solution in water), 
hexafluoroacetylacetone (99\%), and sodium hydroxide were purchased from Fisher Scientific (Fair Lawn, NJ, USA). Lithium bis[(trifluoromethyl)sulfonyl]imide ( $\operatorname{LiNTf}_{2}$ ) was purchased from SynQuest Laboratories (Alachua, FL, USA). Deuterated dimethylsulfoxide and deuterated chloroform were purchased from Cambridge Isotope Laboratories (Andover, MA, USA). Nitinol wire with a diameter of $128 \mu \mathrm{m}$ was purchased from Nitinol Devices \& Components (Fremont, CA, USA). Deionized water $(18.2 \mathrm{M} \Omega \mathrm{cm})$ was obtained from a Milli-Q water purification system (Millipore, Bedford, MA, USA).

A commercial blend of roasted coffee beans was purchased from a local market and subsequently ground with a commercial coffee grinder.

\subsection{Synthesis of ionic liquid monomers and crosslinkers and fabrication of PIL-based SPME fibers}

Table 1 lists the IL monomer/crosslinker composition of the crosslinked PIL-based SPME fiber coatings that were evaluated in this study. 1-Vinylbenzyl-3-hexadecylimidazolium bis[(trifluoromethyl)sulfonyl]imide [VBHDIM] [NTf 2 ], 1-vinyl-3-(10-hydroxydecyl)imidazolium bis[(trifluoromethyl)sulfonyl]imide $\quad\left[\mathrm{VC}_{10} \mathrm{OHIM}\right] \quad\left[\mathrm{NTf}_{2}\right], \quad$ and $\quad$ 1,12-di(3-vinylbenzylimidazolium)dodecane dibis[(trifluoromethyl)sulfonyl]imide [(VBIM) $\left.)_{2} \mathrm{C}_{12}\right] 2\left[\mathrm{NTf}_{2}\right]$ were prepared according to previously published methods $[13,14]$. The synthesis of 1-vinyl-3-(9-carboxy nonyl)imidazolium bis[(trifluoromethyl)sulfonyl]imide [ $\left.\mathrm{VC}_{9} \mathrm{COOHIM}\right] \quad\left[\mathrm{NTf}_{2}\right]$, 1,12-di(3-vinyl benzylimidazolium)dodecane dihexafluoroacetylacetonate $\left[(\mathrm{VBIM})_{2} \mathrm{C}_{12}\right] 2\left[\mathrm{~F}_{6}\right.$-acac $]$ and 1,12-di(3vinylbenzylbenzimidazolium)dodecane $\quad \operatorname{dibis}\left[\left(\right.\right.$ trifluoromethyl)sulfonyl]imide $\quad\left[(\mathrm{VBBIM})_{2} \mathrm{C}_{12}\right]$ $2\left[\mathrm{NTf}_{2}\right]$ is reported in the Supporting Information. All IL monomers and crosslinkers were fully characterized by ${ }^{1} \mathrm{H}-\mathrm{NMR}$ and the spectral data are reported in the Supporting Information. ${ }^{1} \mathrm{H}$ NMR spectra were collected in deuterated dimethyl sulfoxide using a Bruker DRX $500 \mathrm{MHz}$ nuclear magnetic resonance (NMR) spectrometer (Billerica, MA, USA). 
All PIL-based fibers, composed of a coating mixture consisting of IL monomer, IL crosslinker (50\% by weight with respect to the monomer), and DAROCUR 1173 photoinitiator (3\% by weight with respect to the coating mixture), were prepared on derivatized NiTi wires as described previously [13]. A coating length of $1.3 \mathrm{~cm}$ was maintained for all fibers examined in this study. The approximate film thickness of the PIL sorbent coatings, examined using a JEOL JSM6060 LV low vacuum scanning electron microscope (SEM), was determined on at least 5 segments for each fiber and is reported in Table 1.

\subsection{Standard and sample preparation}

Individual stock solutions of acrylamide and menthol (used as an internal standard) were prepared in a $20 \mathrm{~mL}$ sealed vial by dissolving $2 \mathrm{mg}$ of the pure standard in deionized water to obtain a concentration of $100 \mathrm{mg} \mathrm{L}^{-1}$. Working standards of acrylamide were prepared by pipetting appropriate amounts of the stock standard and $10 \mu \mathrm{L}$ of the menthol internal standard stock solution (final concentration $50 \mu \mathrm{g} \mathrm{L}^{-1}$ ) into a $20 \mathrm{~mL}$ sealed vial and further diluted with deionized water to obtain a final volume of $20 \mathrm{~mL}$. A $2 \%$ (w/v) ethanolic ninhydrin solution was prepared in a $20 \mathrm{~mL}$ sealed vial by dissolving $400 \mathrm{mg}$ of pure ninhydrin in $20 \mathrm{~mL}$ of ethanol.

Brewed coffee samples were prepared using a household American coffee maker from $35 \mathrm{~g}$ of ground coffee extracted with $600 \mathrm{~mL}$ of tap water. Before analysis, a $19 \mathrm{~mL}$ aliquot of the brewed coffee was mixed with $10 \mu \mathrm{L}$ of the menthol internal standard stock solution (final concentration $50 \mu \mathrm{g} \mathrm{L}^{-1}$ ) and $1 \mathrm{~mL}$ of $2 \%(\mathrm{w} / \mathrm{v})$ ethanolic ninhydrin solution in a $20 \mathrm{~mL}$ sealed vial. Roasted coffee powder samples were prepared by transferring $2 \mathrm{~g}$ of ground roasted coffee into a 20 $\mathrm{mL}$ sealed vial containing $17 \mathrm{~mL}$ of deionized water. Subsequently, $10 \mu \mathrm{L}$ of the menthol internal standard stock solution and $1 \mathrm{~mL}$ of $2 \%(\mathrm{w} / \mathrm{v})$ ethanolic ninhydrin solution were added to the suspension. Reaction quenching by ninhydrin was carried out for both brewed coffee and coffee powder by placing the solution vial into a water bath thermostated at $80{ }^{\circ} \mathrm{C}$ (with constant agitation at $1500 \mathrm{rpm}$ ) for 10 minutes. Sampling was performed immediately after the reaction. 


\subsection{Sampling and quantitation of acrylamide in brewed coffee and coffee powder}

Sampling was carried out by directly immersing the PIL fiber into the sample solution under the following conditions: solution temperature: $25^{\circ} \mathrm{C}$, extraction time: $30 \mathrm{~min}$; sample agitation: $1500 \mathrm{rpm}$. A temperature of $25^{\circ} \mathrm{C}$ was selected to prevent the formation of new acrylamide in the sample at higher temperatures. The extraction time was optimized by sampling a $2.5 \mu \mathrm{g} \mathrm{L}^{-1}$ solution of acrylamide with Fiber 1 (see Table 1) at 5, 15, 30, 45 and $60 \mathrm{~min}$. The analytes were then desorbed in the $\mathrm{GC}$ inlet at $220{ }^{\circ} \mathrm{C}$ for $5 \mathrm{~min}$. Following each desorption step, the PIL fibers were immersed in $20 \mathrm{~mL}$ of deionized water for $5 \mathrm{~min}$ to remove any impurities extracted from the coffee matrix. The fiber was then re-conditioned in the GC inlet for 5 minutes at $220{ }^{\circ} \mathrm{C}$ to remove residual moisture from the coating. With this conditioning procedure, PIL fibers $\mathbf{1}, \mathbf{5}$ and $\mathbf{7}$ were subjected to more than 100 analyses (included real-world coffee samples) and were found to maintain comparable extraction performance as well as an unaltered coating texture.

Quantitative analysis of acrylamide in brewed coffee and coffee powder was performed by the method of standard addition optimized in a previous study [12]. Brewed coffee samples were fortified with 0,50 and $100 \mu \mathrm{g} \mathrm{L}^{-1}$ of acrylamide by spiking appropriate amounts of the stock standard into the sample solution. Coffee powder suspensions were spiked in the same mode to obtain a fortification of 0,1 and $2 \mu \mathrm{g} \mathrm{g}^{-1}$ of acrylamide. All coffee samples were subjected to reaction quenching using ninhydrin, as described previously. Each analysis was performed in triplicate. Once a linear calibration curve was obtained from the spiking experiments, the data were then extrapolated to calculate the concentration of acrylamide in the unspiked sample.

\subsection{Instrument parameters}

Analyses were performed using an Agilent 7890B gas chromatograph coupled with an Agilent 5977A mass spectrometer equipped with the MassHunter B.07.00 software (Agilent, Santa Clara, CA, USA). The GC split/splitless injector temperature was maintained at $220{ }^{\circ} \mathrm{C}$ and 
operated in split mode $(5: 1)$ during analyte desorption. Helium was used as the carrier gas and maintained at a constant flow of $1 \mathrm{~mL} \mathrm{~min}^{-1}$. A Mega-FFAP-EXT column $\left(50 \mathrm{~m} \times 0.20 \mathrm{~mm} d_{c} \mathrm{x}\right.$ $0.20 \mu \mathrm{m} d_{f}$ ) (Legnano, MI, Italy) was used for the separation. The following oven temperature programs were applied: i) initial temperature of $50{ }^{\circ} \mathrm{C}$ ramped to $250{ }^{\circ} \mathrm{C}$ at $7.5^{\circ} \mathrm{C} / \mathrm{min}$ (held for 1.5 min) for the analysis of the acrylamide standard solutions and ii) initial temperature of $50{ }^{\circ} \mathrm{C}$ (held for $0.9 \mathrm{~min}$ ), ramped to $170{ }^{\circ} \mathrm{C}$ at $2.5^{\circ} \mathrm{C} / \mathrm{min}$, then ramped to $250{ }^{\circ} \mathrm{C}$ at $5{ }^{\circ} \mathrm{C} / \mathrm{min}$ (held for $5 \mathrm{~min}$ ) for the analysis of the coffee samples. The MS was operated in electron ionization mode (EI) at 70 $\mathrm{eV}$ for all analyses. Data were initially acquired in SCAN mode (mass range: $35-350 \mathrm{~m} / \mathrm{z}$ ) to locate and identify acrylamide and the internal standard in the samples. Subsequently, single ion monitoring (SIM) acquisition mode was used for the detection/quantitation of acrylamide (dwell time: 100 msec, target ion: $71 \mathrm{~m} / \mathrm{z}$, qualifier ion: $55 \mathrm{~m} / \mathrm{z}$ ). The LOD and limit of quantitation (LOQ) were determined based on a 3:1 (signal:noise) and 10:1 ratio, respectively.

\section{Results and Discussion}

This section includes a description of the crosslinked PIL-based sorbent fiber coatings followed by the evaluation of both their analytical performance for the extraction of acrylamide as well as its determination in coffee samples. The approximate film thicknesses of the fibers were obtained by vacuum scanning electron microscopy, which required the fibers to be sacrificed prior to imaging.

\subsection{Structural design of crosslinked PIL-based sorbent coatings}

Nine different PIL-based sorbent coatings based on the combination of various IL monomers and crosslinkers were prepared in this study to examine their selectivity towards acrylamide for comparison to the previously reported fiber [12] consisting of $50 \%(\mathrm{w} / \mathrm{w})$ $\left[(\mathrm{VIM})_{2} \mathrm{C}_{12}\right] 2\left[\mathrm{NTf}_{2}\right]$ in [VBHDIM] $\left.\left[\mathrm{NTf}_{2}\right]\right)$ as the reference fiber (Ref.) [12]. Table 1 reports the composition of all nine sorbent coatings. The structure of the monomer was tailored by 
incorporating hydroxyl moieties in Fibers 2, 5 and 8, and carboxylic acid moieties into Fibers 3, 6 and 9. The structure of the crosslinker was also varied by introducing an aromatic moiety (e.g., the vinylbenzyl substituent) to all of the fibers. The benzimidazolium cation was introduced into the crosslinker structure of Fibers 4, 5 and $\mathbf{6}$ and the $\left[\mathrm{F}_{6}\right.$-acac] anion was incorporated for the first time in a PIL structure in Fibers 7, 8 and 9.

\subsection{Analytical performance of the PIL-based fibers for the extraction of acrylamide}

The extraction efficiency and the analytical performance of the nine PIL-based SPME coatings, including the analytical precision, linearity, LOD/LOQ, and fiber-to-fiber reproducibility, was evaluated by in-solution extraction of aqueous solutions spiked with acrylamide at different concentration levels.

The extraction efficiency of the new coatings was first tested by analyzing a $50 \mu \mathrm{g} \mathrm{L} \mathrm{L}^{-1}$ acrylamide solution with the nine fibers and the results compared to those obtained with the reference fiber. The results are reported in Figure 1 (grey bars). Fibers 1, 5, 7 and $\mathbf{8}$ showed higher extraction efficiencies than the reference fiber with the highest efficiency being produced by Fiber

5.

These results were confirmed by determining the LOD and the LOQ values, as shown in Table 2. The LOD was $0.1 \mu \mathrm{g} \mathrm{L}^{-1}$ for Fiber 5 and $0.5 \mu \mathrm{g} \mathrm{L}^{-1}$ for Fibers $\mathbf{1 ,} 7$ and $\mathbf{8}$ while the LOQ was $0.5 \mu \mathrm{g} \mathrm{L}^{-1}$ for Fiber 5 and $1 \mu \mathrm{g} \mathrm{L}^{-1}$ for Fibers 1, 7 and 8. In all cases, their LOQs were one to two orders of magnitude lower than that of the reference fiber $\left(10 \mu \mathrm{g} \mathrm{L}^{-1}\right)$ [12]. The linearity of the calibration curves was also studied using the nine fibers at different concentration levels starting from the LOQ for each fiber. The calibration levels were $0.5,1,10,50,100$ and $200 \mu \mathrm{g} \mathrm{L}^{-1}$. As shown in Table 2, all nine PIL-based fibers showed excellent linearity with correlation coefficients $\left(\mathrm{R}^{2}\right)$ above 0.99 . 
The analytical precision of the fibers was evaluated by triplicate analyses at each calibration level. Table 2 reports the percent relative standard deviation (\% RSD) obtained by analyzing the 50 $\mu \mathrm{g} \mathrm{L}^{-1}$ acrylamide solution with the nine fibers. The results were highly satisfactory with \% RSD lower than $9 \%$ for all fibers.

The fiber-to-fiber reproducibility was also studied for Fibers $\mathbf{1}$ and $\mathbf{5}$. An additional fiber for each coating was made and the fiber-to-fiber reproducibility was determined by evaluating \%RSD from the analysis of a $50 \mu \mathrm{g} \mathrm{L}^{-1}$ acrylamide solution. A \% RSD of $10.9 \%$ and $10.1 \%$ was obtained for Fiber $\mathbf{1}$ and Fiber 5, respectively. These results indicate that the two replicates of the same fiber also possess very similar film thickness.

3.3. Compatibility of different PIL-based fibers with complex real-word samples: quantitation of acrylamide in brewed coffee and coffee powder

The matrix-compatibility of the PIL-based coatings with complex real-word samples was examined through the quantitation of acrylamide in brewed coffee and coffee powder with Fibers $\mathbf{1}$, 5 and 7, which showed the best extraction efficiency towards acrylamide. Each fiber possessed different crosslinkers, as shown in Table 1.

Samples of brewed coffee and coffee powder were analyzed using the method previously reported [12]. Quantitative analysis was carried out by the method of standard addition after a quenching reaction using ninhydrin to selectively degrade free asparagine extracted from the sample and inhibit the formation of interfering acrylamide during the thermal desorption step.

Fibers 1, 5 and 7 were first applied to the in-solution extraction of the same brewed coffee. Individual brewed coffee samples were spiked with varying amounts of acrylamide to generate a calibration curve for each fiber. The resulting chromatograms are shown in Figure 2. Table 3 reports the figures of merits of the calibration curves together with the extrapolated concentration of acrylamide. The results showed calibration curves with excellent linearity $\left(\mathrm{R}^{2}>0.99\right)$. The 
extrapolated concentration of acrylamide in the brewed coffee was determined to be $77 \mu \mathrm{g} \mathrm{L}^{-1}, 82$ $\mu \mathrm{g} \mathrm{L}^{-1}$ and $73 \mu \mathrm{g} \mathrm{L}^{-1}$ for Fibers 1, 5 and 7, respectively, with excellent reproducibility (5.9\% RSD).

Two g of the ground coffee samples were suspended in water to quantify the amount of acrylamide present in the roasted coffee beans, and then analyzed by in-solution SPME using Fibers 1, 5 and 7. The suspensions were fortified with 0,1 and $2 \mu \mathrm{g} \mathrm{g}^{-1}$ of acrylamide to generate a calibration curve. Figure S7 (Supporting Information) reports the profile obtained with Fiber 5. An excellent linearity of the calibration curve was obtained $\left(\mathrm{R}^{2}>0.99\right)$ for all fibers (Table 3$)$. The extrapolated concentration of acrylamide in the unspiked coffee powder with Fibers $\mathbf{1}, \mathbf{5}$ and $\mathbf{7}$ was $502 \mu \mathrm{g} \mathrm{kg}^{-1}, 512 \mu \mathrm{g} \mathrm{kg}^{-1}$ and $586 \mu \mathrm{g} \mathrm{kg}^{-1}$, respectively. The reproducibility of the acrylamide results within the same set of fibers was very good also for the coffee powder with a \%RSD of 9.1 $\%$, demonstrating that all PIL-based coatings developed in this study can be used to determine acrylamide accurately in coffee samples.

The matrix-compatibility of the PIL-based coatings was also confirmed by examining SEM micrographs of the fibers that were subjected to the analysis of the coffee samples. Figure S8 (Supporting Information) compares the micrographs of the coatings of the nine PIL-based fibers. The micrographs show that the texture of the coatings for Fibers $\mathbf{1 ,} \mathbf{5}$ and $\mathbf{7}$ is similar to that of the fibers with the same crosslinker but not subjected to analysis of coffee. These results reveal that the coating is apparently not altered when sampling the complex coffee matrices.

3.4. Evaluation of the approximate PIL coating film thickness and its effect towards acrylamide selectivity

The approximate film thickness of the nine PIL sorbent coatings was estimated by examining the micrographs of all fibers obtained with a low vacuum scanning electron microscope (SEM). A representative micrograph of each fiber is reported in Figure S8 (Supporting Information) while their approximate film thickness is reported in Table 1. 
A comparison of the micrographs shows that the texture of the coating surface appears to be influenced by the structure of the crosslinker. Fibers containing the $\left[(\mathrm{VBIM})_{2} \mathrm{C}_{12}\right] 2\left[\mathrm{NTf}_{2}\right]$ and $\left[(\mathrm{VBBIM})_{2} \mathrm{C}_{12}\right] 2\left[\mathrm{NTf}_{2}\right]$ crosslinkers produced a smooth surface, while anion exchange with the $\left[\mathrm{F}_{6}\right.$-acac $]$ anion yielded fibers with a more ruffled surface morphology.

The acrylamide peak area and the approximate film thickness of the fibers wereas also used to normalize the extraction efficiency of the PIL sorbent coatings toward acrylamide. The normalized peak areas are reported in Figure 1 (black bars). By comparing the results of the normalized extraction efficiency within each series of crosslinker, it can be observed that the hydroxyl moiety appended to the IL monomer increases the sensitivity of the PIL coatings toward acrylamide. Fibers $\mathbf{2 ,} 5$ and $\mathbf{8}$ exhibited higher normalized peak areas than the corresponding coatings consisting of monomers with alkyl chains containing the carboxylic acid moiety or without any functional groups. The performance of the new nine fibers was also compared by evaluating their "concentration factors" (CF) obtained by calculating the ratio between the normalized peak areas and the normalized peak area of the reference fiber [12] (see Table 2). CFs ranged from 0.38 for Fiber 9 to 2.73 for Fiber 2. From these results, it is clear that the film thickness strongly affects recovery, the $\left[(\mathrm{VBIM})_{2} \mathrm{C}_{12}\right] 2\left[\mathrm{NTf}_{2}\right]$ crosslinker provides thicker coatings, while the highest concentration factors are obtained with monomers containing the hydroxyl moiety.

\section{Conclusions}

A series of nine crosslinked PIL-based SPME sorbent coatings was prepared and tested for the trace-level extraction of acrylamide in brewed coffee and coffee powder. All PIL fibers showed good analytical precision and linearity. Several coatings exhibited superior sensitivity compared to previously investigated commercial and PIL-based coatings. The limit of quantitation for insolution SPME extraction of acrylamide from aqueous solutions was in the low $\mu \mathrm{g} \mathrm{L}^{-1}$ range for several PILs coatings, with a limit of quantitation of $0.5 \mu \mathrm{g} \mathrm{L}^{-1}$ obtained with the $50 \%$ $\left[(\mathrm{VBBIM})_{2} \mathrm{C}_{12}\right] 2\left[\mathrm{NTf}_{2}\right]$ in [ $\left.\mathrm{VC}_{10} \mathrm{OHIM}\right]\left[\mathrm{NTf}_{2}\right]$ coating. Normalization of the extraction efficiency 
to the experimentally measured film thickness of the sorbent coating enabled also to show that the hydroxyl moiety appended to the IL cation has a significant effect on the sensitivity of the PIL coatings toward acrylamide. The matrix-compatibility of the PIL-based fibers with complex realworld samples was proven through the quantitation of acrylamide in brewed coffee and coffee powder.

\section{Acknowledgements}

J.L.A. acknowledges support from the Chemical Measurement and Imaging Program in the Division of Chemistry at the National Science Foundation (CHE-1413199). C.C. and C.B. acknowledge support from the Ricerca Locale (Ex 60\% 2015) of the University of Turin, Turin (Italy). Stephen Pierson and Omprakash Nacham are thanked for their assistance in preparing IL monomers and crosslinkers in this study.

\section{References}

[1] A.A. Elbashir, M.M. Omar, W.A. Ibrahim, O.J. Schmitz, H.Y. Aboul-Enein, Acrylamide analysis in food by liquid chromatographic and gas chromatographic methods, Crit. Rev. Anal. Chem., 44 (2014) 107-141.

[2] D.S. Mottram, B.L. Wedzicha, A.T. Dodson, Acrylamide is formed in the Maillard reaction, Nature, 419 (2002) 448-449.

[3] R.H. Stadler, I. Blank, N. Varga, F. Robert, J. Hau, P.A. Guy, M.C. Robert, S. Riediker, Acrylamide from Maillard reaction products, Nature, 419 (2002) 449-450.

[4] J. Park, L.M. Kamendulis, M.A. Friedman, J.E. Klaunig, Acrylamide-induced cellular transformation, Toxicol. Sci., 65 (2002) 177-183.

[5] J.M. Rice, The carcinogenicity of acrylamide, Mutat. Res.-Gen. Tox. En., 580 (2005) 3-20.

[6] EFSA CONTAM Panel (EFSA Panel on Contaminants in the Food Chain), Scientific Opinion on acrylamide in food, EFSA J. 13 (2015) 4104-4321.

[7] R.C. Alves, C. Soares, S. Casal, J.O. Fernandes, M.B.P.P. Oliveira, Acrylamide in espresso coffee: influence of species, roast degree and brew length, Food Chem., 119 (2010) 929-934. 
[8] P.C. Aguas, M.J. Fitzhenry, G. Giannikopoulos, P. Varelis, Analysis of acrylamide in coffee and cocoa by isotope dilution liquid chromatography-tandem mass spectrometry, Anal. Bioanal. Chem., 385 (2006) 1526-1531.

[9] J. Oracz, E. Nebesny, D. Zyzelewicz, New trends in quantification of acrylamide in food products, Talanta, 86 (2011) 23-34.

[10] L. Dunovska, T. Cajka, J. Hajslova, K. Holadova, Direct determination of acrylamide in food by gas chromatography-high-resolution time-of-flight mass spectrometry, Anal. Chim. Acta, 578 (2006) 234-240.

[11] Y.H. Zhu, G.R. Li, Y.P. Duan, S.Q. Chen, C. Zhang, Y.F. Li, Application of the standard addition method for the determination of acrylamide in heat-processed starchy foods by gas chromatography with electron capture detector, Food Chem., 109 (2008) 899-908.

[12] C. Cagliero, T.D. Ho, C. Zhang, C. Bicchi, J.L. Anderson, Determination of acrylamide in brewed coffee and coffee powder using polymeric ionic liquid-based sorbent coatings in solidphase microextraction coupled to gas chromatography-mass spectrometry, J. Chromatogr. A 1449 (2016) 2-7.

[13] T.D. Ho, B.R. Toledo, L.W. Hantao, J.L. Anderson, Chemical immobilization of crosslinked polymeric ionic liquids on nitinol wires produces highly robust sorbent coatings for solid-phase microextraction, Anal. Chim. Acta, 843 (2014) 18-26.

[14] H. Yu, J. Merib, J.L. Anderson, Crosslinked polymeric ionic liquids as solid-phase microextraction sorbent coatings for high performance liquid chromatography, J. Chromatogr. A, 1438 (2016) 10-21. 


\section{Figure Captions}

Figure 1: Comparison of the acrylamide extraction efficiency in an aqueous solution $\left(50 \mu \mathrm{g} \mathrm{L}^{-1}\right)$ using the nine investigated PIL-based SPME coatings and the reference PIL fiber. Grey bars represent the mean of the absolute peak areas of acrylamide obtained by three replicate extractions and the black bars represent the areas normalized by the approximate film thickness of each fiber (see Table 1). The nine investigated PIL-based coatings are divided using different shadings based on the crosslinker: $\square\left[(\mathrm{VBIM})_{2} \mathrm{C}_{12}\right] 2\left[\mathrm{NTf}_{2}\right]$ crosslinker, $\square\left[(\mathrm{VBBIM})_{2} \mathrm{C}_{12}\right] 2\left[\mathrm{NTf}_{2}\right]$ crosslinker, and $\square\left[(\mathrm{VBIM})_{2} \mathrm{C}_{12}\right] 2\left[\mathrm{~F}_{6}\right.$-acac $]$ crosslinker.

Figure 2: Selected ion monitoring (SIM) GC-MS profiles of in-solution extraction from brewed coffee spiked with $100 \mu \mathrm{g} \mathrm{L}^{-1}$ of acrylamide obtained with Fiber 1 (a1), Fiber 5 (b1) and Fiber 7 (c1) and a comparison between the levels of acrylamide observed in the extraction of the coffee brew unspiked (pink) and spiked with $50 \mu \mathrm{g} \mathrm{L}^{-1}$ (blue) and $100 \mu \mathrm{g} \mathrm{L}^{-1}$ (black) of acrylamide with Fiber 1 (a2), Fiber 5 (b2), and Fiber 7 (c2). 


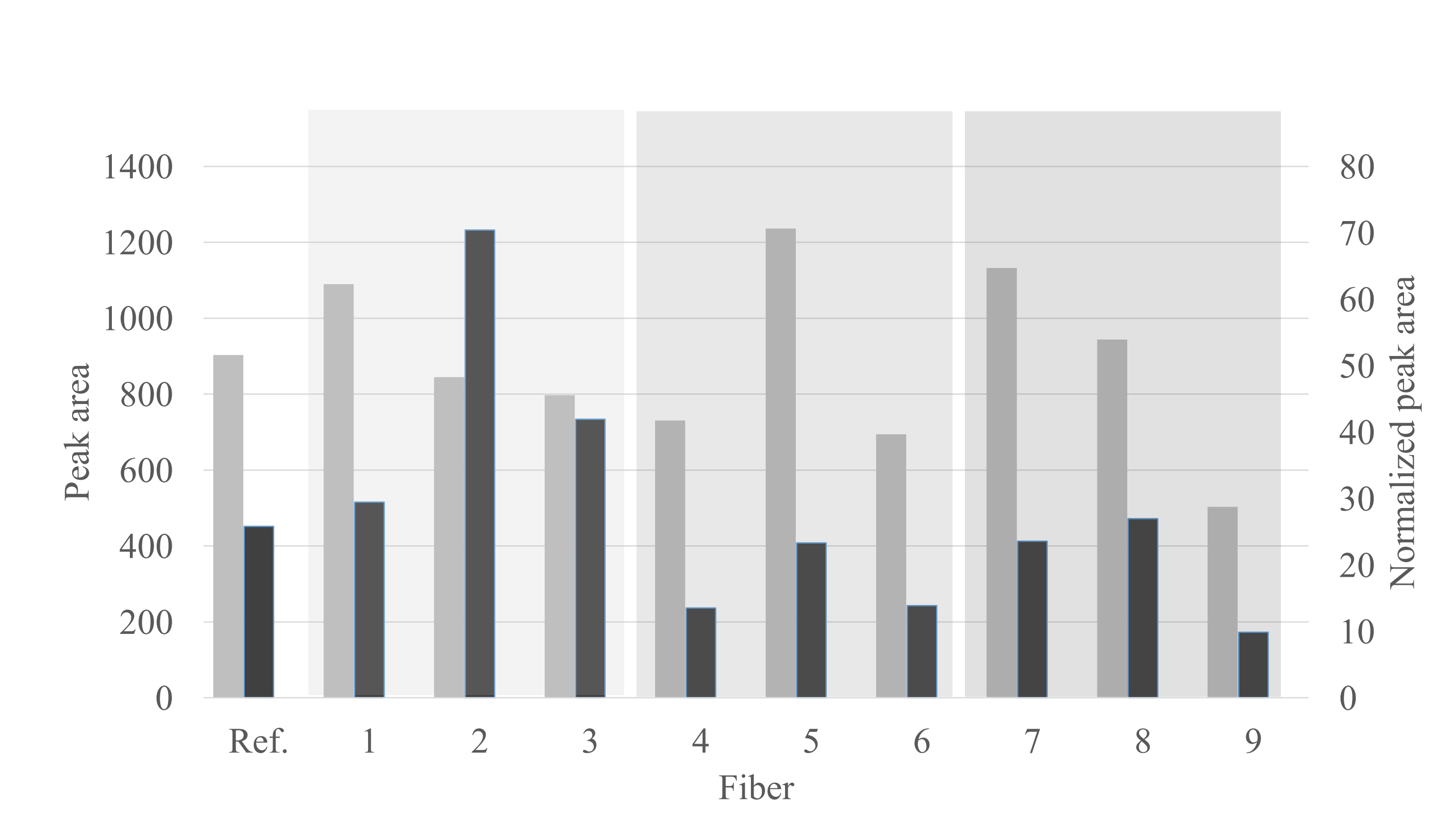

Area $\square$ Normalized area

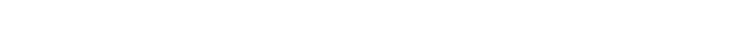

are

(

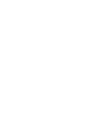

Normal

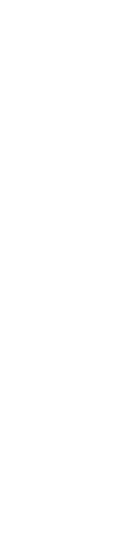

.

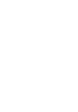

列

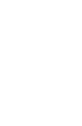

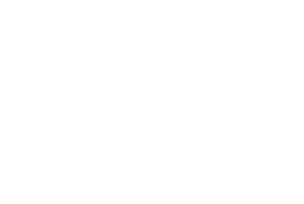

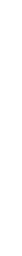

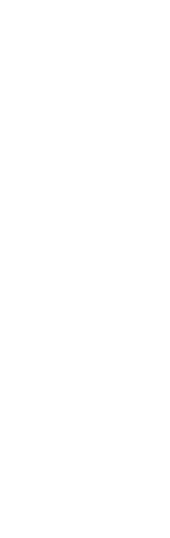

(2)
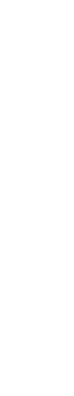

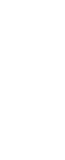
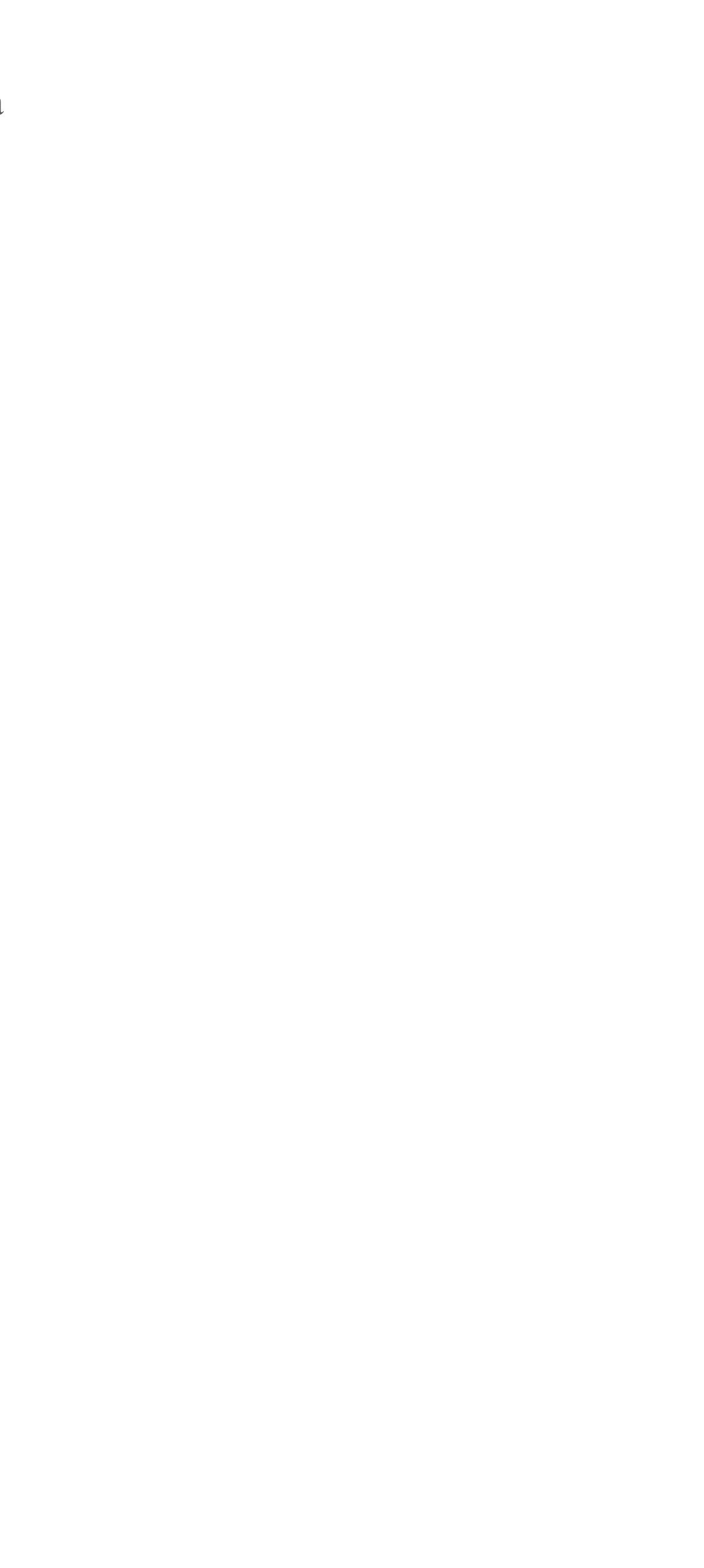
Figure 2
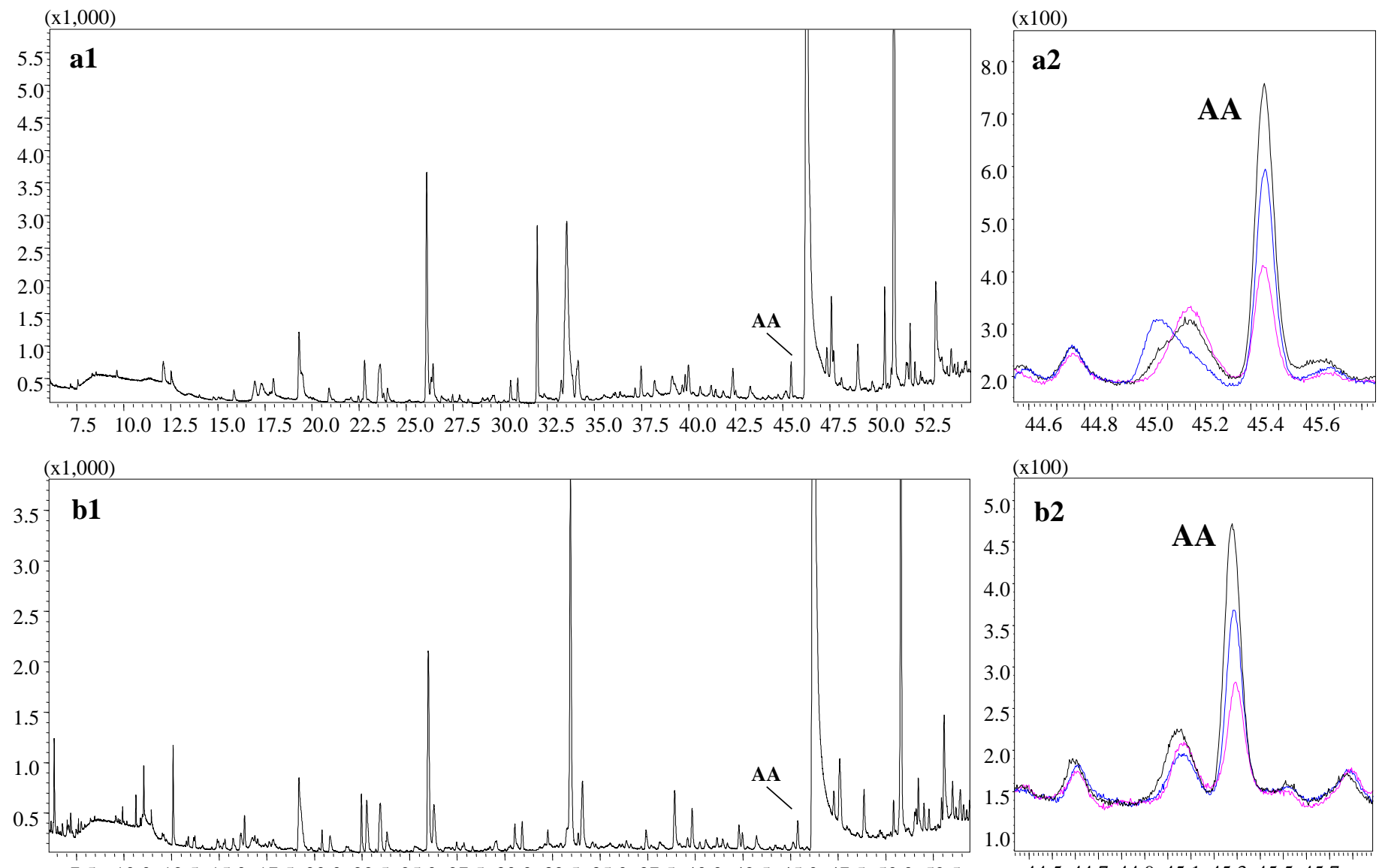

$\begin{array}{lllllllllllllllllll}7.5 & 10.0 & 12.5 & 15.0 & 17.5 & 20.0 & 22.5 & 25.0 & 27.5 & 30.0 & 32.5 & 35.0 & 37.5 & 40.0 & 42.5 & 45.0 & 47.5 & 50.0 & 52.5\end{array}$

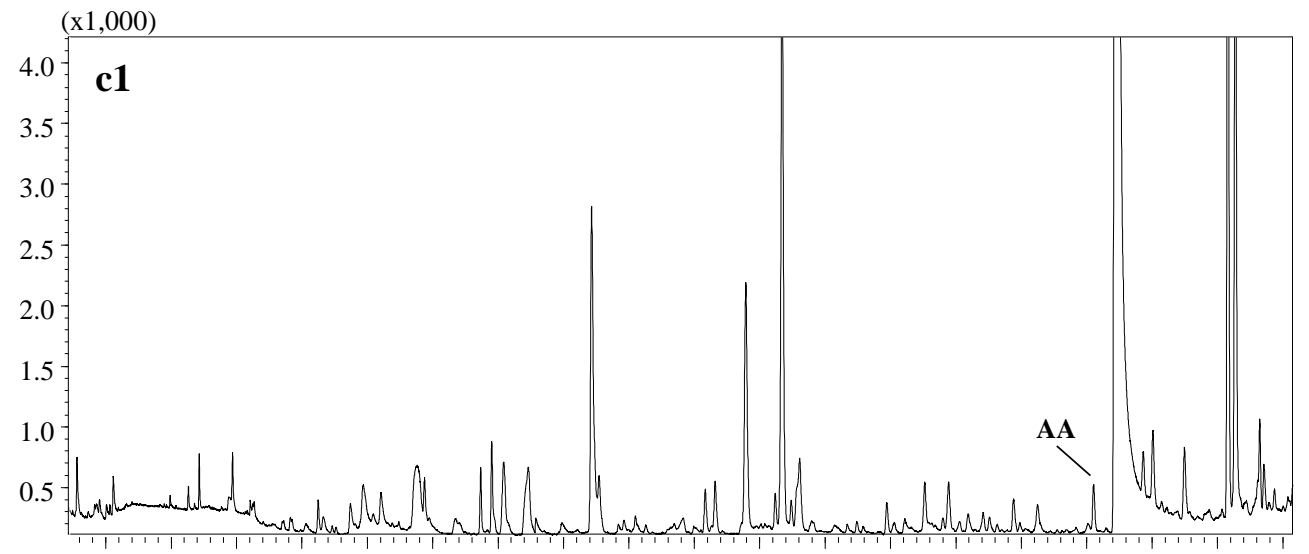

$\begin{array}{lllllllllllllllllll}7.5 & 10.0 & 12.5 & 15.0 & 17.5 & 20.0 & 22.5 & 25.0 & 27.5 & 30.0 & 32.5 & 35.0 & 37.5 & 40.0 & 42.5 & 45.0 & 47.5 & 50.0 & 52.5\end{array}$

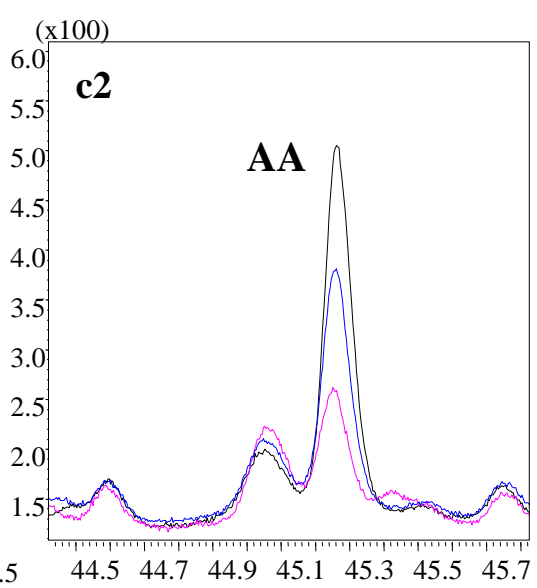


Table 1. Structural composition and approximate film thickness of all PIL-based sorbent coatings examined in this study

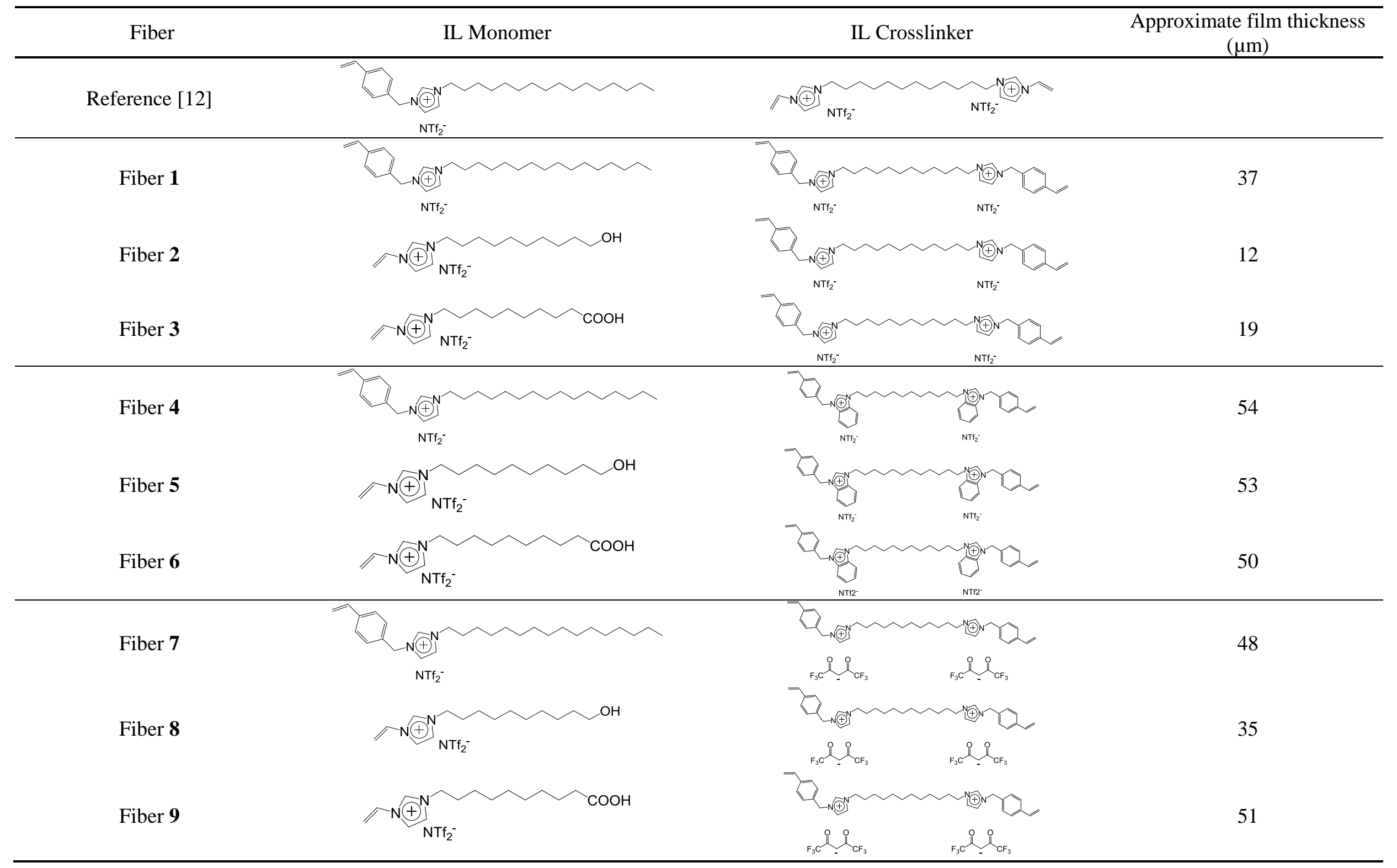


Table 2. Figures of merit for all PIL-based sorbent coatings examined in this study for the analysis of aqueous acrylamide solutions.

\begin{tabular}{|c|c|c|c|c|c|c|c|}
\hline Fiber & $\begin{array}{l}\text { Linear range } \\
\qquad\left(\mu \mathrm{g} \mathrm{L}^{-1}\right)\end{array}$ & Slope \pm error & Linearity $\left(\mathrm{R}^{2}\right)$ & $\operatorname{LOD}\left(\mu \mathrm{g} \mathrm{L}^{-1}\right)$ & $\operatorname{LOQ}\left(\mu \mathrm{g} \mathrm{L}^{-1}\right)$ & $\begin{array}{c}\% \mathrm{RSD} 50 \mu \mathrm{g} \mathrm{L}^{-1} \\
(n=3)\end{array}$ & $\begin{array}{c}\text { Concentration } \\
\text { factors }^{\mathrm{a}}\end{array}$ \\
\hline Fiber 1 & $1-200$ & $12.5 \pm 0.19$ & 0.999 & 0.5 & 1 & 3.7 & 0.98 \\
\hline Fiber 2 & $10-200$ & $8.3 \pm 0.13$ & 0.999 & 1.0 & 10 & 2.5 & 2.73 \\
\hline Fiber 3 & $10-200$ & $11.2 \pm 0.20$ & 0.999 & 1.0 & 10 & 9.0 & 1.63 \\
\hline Fiber 4 & $10-200$ & $11.5 \pm 0.38$ & 0.997 & 1.0 & 10 & 6.3 & 0.52 \\
\hline Fiber 5 & $0.5-200$ & $13.4 \pm 0.55$ & 0.995 & 0.1 & 0.5 & 7.1 & 0.90 \\
\hline Fiber 6 & $10-200$ & $12.1 \pm 0.12$ & 0.999 & 1.0 & 10 & 7.3 & 0.54 \\
\hline Fiber 7 & $1-200$ & $11.1 \pm 0.43$ & 0.997 & 0.5 & 1 & 8.2 & 0.91 \\
\hline Fiber 8 & $1-200$ & $9.3 \pm 0.03$ & 0.999 & 0.5 & 1 & 2.2 & 1.05 \\
\hline Fiber 9 & $10-200$ & $7.5 \pm 0.15$ & 0.999 & 1.0 & 10 & 5.7 & 0.38 \\
\hline
\end{tabular}

${ }^{\mathrm{a}}$ Ratio between the peak areas obtained by sampling a $50 \mu \mathrm{g} \mathrm{L}{ }^{-1}$ acrylamide water solution normalized by the approximate film thickness of the fiber and the normalized peak area of the reference fiber [12]. 
Table 3. Comparison of the quantification results and figures of merit obtained with Fibers $\mathbf{1}, \mathbf{5}$ and $\mathbf{7}$ in the determination of acrylamide (AA) from brewed coffee and coffee powder by the method of standard addition.

\begin{tabular}{|c|c|c|c|c|c|c|c|c|c|c|}
\hline & \multicolumn{3}{|c|}{ Fiber 1} & \multicolumn{3}{|c|}{ Fiber 5} & \multicolumn{3}{|c|}{ Fiber 7} & \multirow{2}{*}{$\begin{array}{c}\text { Reproducibility } \\
\text { (\%) RSD }\end{array}$} \\
\hline & $\begin{array}{c}\text { Slope } \pm \\
\text { error }\end{array}$ & $\begin{array}{c}\text { Linearity } \\
\left(\mathrm{R}^{2}\right)\end{array}$ & $\begin{array}{c}\text { AA } \\
\text { amount }\end{array}$ & $\begin{array}{c}\text { Slope } \pm \\
\text { error }\end{array}$ & $\begin{array}{c}\text { Linearity } \\
\left(\mathrm{R}^{2}\right)\end{array}$ & $\begin{array}{c}\text { AA } \\
\text { amount }\end{array}$ & $\begin{array}{l}\text { Slope } \pm \\
\text { error }\end{array}$ & $\begin{array}{c}\text { Linearity } \\
\left(\mathrm{R}^{2}\right)\end{array}$ & $\begin{array}{c}\mathrm{AA} \\
\text { amount }\end{array}$ & \\
\hline Brewed coffee & $15.3 \pm 0.43$ & 0.999 & $77 \mu \mathrm{g} \mathrm{L}^{-1}$ & $8.85 \pm 0.04$ & 0.999 & $82 \mu \mathrm{g} \mathrm{L}^{-1}$ & $12.82 \pm 0.85$ & 0.995 & $73 \mu \mathrm{g} \mathrm{L}^{-1}$ & $5.9 \%$ \\
\hline Coffee powder & $786 \pm 36$ & 0.998 & $502 \mu \mathrm{g} \mathrm{kg}^{-1}$ & $732 \pm 9.9$ & 0.999 & $513 \mu \mathrm{g} \mathrm{kg}^{-1}$ & $760 \pm 19$ & 0.999 & $586 \mu \mathrm{g} \mathrm{kg}^{-1}$ & $9.1 \%$ \\
\hline
\end{tabular}

